\title{
The taxanes: toxicity and quality of life considerations in advanced ovarian cancer
}

\author{
JP Guastalla III*,I and V Diéras ${ }^{2}$ \\ 'Department of Medical Oncology, Centre Léon Bérard, Lyon, France; ${ }^{2}$ Department of Medical Oncology, Institut Curie, Paris, France
}

\begin{abstract}
The taxanes paclitaxel and docetaxel show good activity in the management of advanced ovarian cancer when used in conjunction with platinum agents. Accumulating evidence from clinical studies, particularly the latest results from the phase III comparative SCOTROC study, indicates that the two drugs confer similar rates of tumour response and survival in women with this condition. However, it is clear that paclitaxel and docetaxel differ in their tolerability profiles and in other respects, and cannot be regarded as directly equivalent drugs. In particular, paclitaxel is associated with significant neurotoxicity; peripheral neuropathy has also been reported with docetaxel, but to a lesser extent. Neutropenia appears more prevalent with docetaxel than with paclitaxel, although clinical trial data show that this adverse effect is manageable and need not compromise dose delivery. Docetaxel is also associated with potential benefits accruing from shorter infusion times and lack of need for premedication with intravenous histamine $\mathrm{H}_{1}$ and $\mathrm{H}_{2}$ antagonists. Emerging quality of life data are expected to shed further light on the overall benefit of chemotherapy in women with advanced ovarian cancer in general, and on taxane-platinum combinations in particular.
\end{abstract}

British Journal of Cancer (2003) 89 (Suppl 3), SI6-S22. doi:I0.I038/sj.bjc.660I 496 www.bjcancer.com

(C) 2003 Cancer Research UK

Keywords: ovarian cancer; paclitaxel; docetaxel; toxicity; quality of life

Despite advances in diagnostic techniques and therapy, cancer of the ovary kills more women than any other tumour of the reproductive system and therefore remains the gynaecological malignancy of greatest concern in industrialised countries (National Library of Medicine, 1994; Dunton, 1997). Only a minority of patients present early enough for complete removal of the tumour to be successful, and chemotherapy is therefore the mainstay of treatment for the majority of women with ovarian cancer (Lister-Sharp et al, 2000) (80\% of patients presented with advanced stage). Two classes of cytotoxic agents, the platinums and the taxanes, have emerged as key components of chemotherapy regimens for advanced disease (Kaye, 2001).

The place of paclitaxel in the treatment of advanced ovarian cancer is well established, but a newer member of the taxane group, docetaxel, has been developed more recently. Docetaxel differs from paclitaxel in a number of respects and represents an alternative taxane with considerable promise and potential tolerability advantages in the management of ovarian cancer (Guastalla et al, 1999; Vasey et al, 1999; Gorbounova et al, 2000; Vasey et al, 2001; Vasey and the Scottish Gynaecological Cancer Trials Group, 2001). In cases where different drugs show similar survival benefit in advanced malignant disease, issues relating to toxicity and quality of life (QoL) become increasingly important.

Current data suggest that the taxanes paclitaxel and docetaxel have similar efficacy, but regimens based on either of these two drugs have shown potentially important differences in their toxicity profiles. As it is always important to balance risks and benefits when setting out treatment plans for individual patients, knowledge of the tolerability differences between the taxanes

*Correspondence: Dr JP Guastalla III; E-mail: guastall@lyon.fnclcc.fr available is clearly necessary for informed treatment decisions to be made. As part of this debate, this article reviews the toxicity profiles of each taxane and discusses QoL issues affecting patients with ovarian cancer.

\section{Clinical benefit of taxane-based chemotherapy}

The clinical benefit in terms of median overall and progressionfree survival of combining paclitaxel rather than an alkylating agent with a platinum compound in stage III-IV (McGuire et al, 1996) or stage IIb-IV (Piccart et al, 2000) disease has been shown in first-line studies in a total of 1057 women. Further data from three major studies in a total of 1798 patients show enhancement of this benefit via improved overall tolerability when cisplatin is replaced by carboplatin (Neijt et al, 2000; du Bois et al, 2003; Ozols et al, 2003).

Concerns over neurotoxicity when paclitaxel and cisplatin are used together have led to evaluation of the combination of docetaxel with cisplatin: three studies of this type of first-line therapy showed encouraging overall clinical response rates of 69-74\% (Guastalla et al, 1999; Vasey et al, 1999; Gorbounova et al, 2000) Neurotoxicity of any grade was reported in 16 and $26 \%$ of patients in two of the studies (Guastalla et al, 1999; Gorbounova et al, 2000), and $23 \%$ of patients in the other trial experienced neurotoxicity of severity greater than grade 1 (Vasey et al, 1999).

In addition, the promise of similar antitumour activity with reduced toxicity (notably neurotoxicity, ototoxicity, nephrotoxicity and gastrointestinal toxicity) when carboplatin is used in place 
of cisplatin as a taxane partner has prompted researchers to explore combinations of docetaxel and carboplatin. A feasibility study of first-line therapy in 139 patients treated with a range of combination dosages of carboplatin plus docetaxel yielded an overall response rate of $66 \%$ and median progression-free survival of 16.6 months, with extremely low levels of neurotoxicity (Vasey et al, 2001). The efficacy and safety of 3-weekly docetaxel 70$75 \mathrm{mg} \mathrm{m}^{-2}$ with carboplatin to achieve an area under the plasma drug concentration vs time curve (AUC) of $5-6 \mathrm{mg} \mathrm{ml}^{-1} \mathrm{~min}^{-1}$ have subsequently been confirmed in a series of three phase II studies in a total of 66 patients (Meyer et al, 1999; Kolevska et al, 2001; Vorobiof et al (2003)). In addition, preliminary comparative data from the Scottish Gynaecological Cancer Trials Group's phase III SCOTROC study in 1077 chemotherapy-naïve patients have indicated that paclitaxel and docetaxel have comparable efficacy when either is combined with carboplatin, but that there are significant differences in the tolerability characteristics of the two regimens (Vasey and the Scottish Gynaecological Cancer Trials Group, 2001).

\section{DOSAGE AND ADMINISTRATION ISSUES}

\section{Dosage and schedule}

Both docetaxel and paclitaxel are usually administered once every 3 weeks. Most patients with ovarian cancer receive paclitaxel as a 3 -h infusion, whereas docetaxel is given over $1 \mathrm{~h}$. This shortened infusion time suggests a potential advantage in terms of patient convenience and other factors such as clinic time and resources for docetaxel.

Although the majority of clinical trials involving the taxanes have involved 3-weekly administration, weekly schedules have also been investigated. There is an underlying pharmacokinetic rationale for such regimens in that they may mimic continuous infusions and thereby increase cellular drug exposure (Boehnke Michaud et al, 2000); weekly regimens have also been linked with reduced levels of myelotoxicity and subsequent potential for optimisation of dose intensity. Phase I data obtained in 18 previously treated patients with relapsed advanced ovarian cancer showed attainment of $90.75 \%$ of planned dose intensity with weekly escalating doses of paclitaxel $\left(40-100 \mathrm{mg} \mathrm{m}^{-2}\right)$ (Fennelly et al, 1997). A $30 \%$ partial response rate was noted in 13 assessable patients, and there was no evidence of cumulative myelosuppression.

Weekly infusions of docetaxel were associated with minimal myelotoxicity in women with advanced refractory ovarian cancer (Hainsworth et al, 1998). Myelosuppression was not dose limiting from $20-52 \mathrm{mg} \mathrm{m}^{-2}$ weekly in 35 evaluable patients. Grade III leucopenia was noted in $14 \%$ of the patients, and there were no reports of grade IV leucopenia or grade III or IV thrombocytopenia or anaemia.

A phase II trial from Japan has evaluated weekly paclitaxel $80 \mathrm{mg} \mathrm{m}^{-2}$ plus carboplatin to AUC $1.5-2.0$ in 17 patients, 14 of whom had advanced ovarian cancer (Kurihara et al, 2001). The overall response rate of $64.7 \%$ included patients who had received previous chemotherapy. Neutropenia of severity greater than grade III was reported in $29.4 \%$ of patients, and QoL as demonstrated by the European Organization for Research and Therapy of Cancer (EORTC) core QLQ-C30 questionnaire suggested that weekly chemotherapy might be better tolerated overall than a 3-weekly schedule. In addition, Markman et al (2002) have recently assessed the effect of increasing the dose intensity of paclitaxel by giving $80 \mathrm{mg} \mathrm{m}^{-2}$ each week to 53 patients who had failed to respond to a conventional 3-weekly regimen consisting of paclitaxel and a platinum agent. An overall objective response rate of $25 \%$ was achieved in this phase II study, and peripheral neuropathy of grade 2 severity or greater was observed in seven patients (13\%) of whom four withdrew from the study.

\section{Premedication guidelines}

Patients receiving taxane therapy require premedication to minimise the risk of hypersensitivity reactions. However, the premedication guidelines recommended for paclitaxel and docetaxel are markedly different (Boehnke Michaud et al, 2000). As indicated in Table 1, patients who receive paclitaxel require both intravenous histamine $\mathrm{H}_{1}$ and $\mathrm{H}_{2}$ antagonists in addition to oral corticosteroids before 1-, 3- or 24-h infusions, although there is some evidence that premedication is not needed before prolonged infusions (those exceeding $96 \mathrm{~h}$ ). By contrast, the premedication regimen recommended for patients receiving docetaxel consists of 3 days' oral dexamethasone (8 $\mathrm{mg}$ twice daily).

Corticosteroid therapy is used in part to prevent hypersensitivity reactions, but major aims are to delay the onset and decrease the severity of fluid retention, and to decrease the frequency and severity of skin and nail changes (Boehnke Michaud et al, 2000). A 5 -day premedication was originally recommended for patients being treated with docetaxel, but this was subsequently reduced to 3 days after the latter regimen was shown to be associated with similar rates of fluid retention and less mucositis and infection.

\section{ADVERSE EVENTS}

\section{Haematological toxicity}

The dose-limiting toxicity of both docetaxel and paclitaxel is neutropenia or, more specifically, febrile neutropenia (Boehnke Michaud et al, 2000). According to collated data from single-agent clinical trials (Aventis Pharmaceuticals Products Inc., 2002), docetaxel $100 \mathrm{mg} \mathrm{m}^{-2}$ over $1 \mathrm{~h}$ every 3 weeks is associated with severe neutropenia $\left(<500\right.$ cells $\mathrm{mm}^{-3}$ ) in $75.4 \%$ of patients; the corresponding rate with paclitaxel $\left(135-300 \mathrm{mg} \mathrm{m}^{-2}\right.$ over $\left.24 \mathrm{~h}\right)$ is reported to be $52 \%$ (Mead Johnson Oncology Products, 2000). At a dose of $250 \mathrm{mg} \mathrm{m}^{-2}$ over $24 \mathrm{~h}$, paclitaxel is associated with an incidence of febrile neutropenia of $16-36 \%$, with other incidences being reported with other infusion durations (Boehnke Michaud

Table I Premedication guidelines for the taxanes

\begin{tabular}{|c|c|c|c|c|c|}
\hline \multirow[b]{2}{*}{ Drugs } & \multicolumn{4}{|c|}{ Paclitaxel } & \multirow{2}{*}{$\frac{\text { Docetaxel }}{\text { I h }}$} \\
\hline & I h & $3 \mathbf{h}$ & $24 \mathrm{~h}$ & $96 \mathrm{~h}$ & \\
\hline Histamine $H_{1}$ antagonist (diphenhydramine 50 mg) & IV prior & IV prior & IV prior & None & None \\
\hline $\begin{array}{l}\text { Histamine } \mathrm{H}_{2} \text { antagonist (cimetidine } 300 \mathrm{mg} \text {, ranitidine } \\
50 \mathrm{mg} \text {, famotidine } 20 \mathrm{mg} \text { ) }\end{array}$ & IV prior & IV prior & IV prior & None & None \\
\hline Dexamethasone & $\begin{array}{l}20 \mathrm{mg} \text { p.o. } \\
12 \text { and } 6 \mathrm{~h} \text { prior }\end{array}$ & $\begin{array}{l}20 \mathrm{mg} \text { p.o. } \\
12 \text { and } 6 \mathrm{~h} \text { prior }\end{array}$ & $\begin{array}{l}20 \mathrm{mg} \text { p.o. } \\
12 \text { and } 6 \mathrm{~h} \text { prior }\end{array}$ & None & $\begin{array}{l}8 \mathrm{mg} \\
\text { twice daily } \times 3 \text { days } \\
\text { starting } 24 \mathrm{~h} \text { prior }\end{array}$ \\
\hline
\end{tabular}


et al, 2000). The rate of febrile neutropenia in patients receiving docetaxel $100 \mathrm{mg} \mathrm{m}^{-2}$ every 3 weeks is reported to be $11 \%$ in patients with normal liver function (Aventis Pharmaceuticals Products Inc., 2002).

Neutropenia is not cumulative with either taxane, and leucocyte counts typically recover 21 days after administration in nearly all patients (Pazdur et al, 1993; Fulton and Spencer, 1996). In almost all patients receiving paclitaxel, white cell counts begin to fall 5-7 days after administration, with a nadir being reached between day 7 and day 14. This phenomenon is seen earlier in docetaxel recipients: white cell counts start to fall 4-6 days after administration, and a nadir is reached between day 6 and day 8 .

The severity of neutropenia can be minimised by the prophylactic addition of colony-stimulating factor to the first course of taxane chemotherapy, or when necessary throughout the treatment cycle (Boehnke Michaud et al, 2000). Clinical practice in this respect varies, with decisions on the use of colony-stimulating factor being based on the regimen being used and types of patient involved, although guidelines (e.g. from the American Society of Clinical Oncology (Ozer et al, 2000) and European Society of Medical Oncology (ESMO, 2001)) are also available.

Grade IV neutropenia was reported in $75 \%$ of 139 patients with stage Ic-IV ovarian cancer who received 3-weekly docetaxel $60-$ $85 \mathrm{mg} \mathrm{m}^{-2}$ plus carboplatin to AUC 5 or 6 in the recent dosefinding study described earlier in this review (Vasey et al, 2001). Preliminary results from the first phase III comparison of docetaxel $\left(75 \mathrm{mg} \mathrm{m}^{-2}\right.$ over $\left.1 \mathrm{~h}\right)$ plus carboplatin to AUC 5 with paclitaxel $\left(175 \mathrm{mg} \mathrm{m}^{-2}\right.$ over $\left.3 \mathrm{~h}\right)$ plus carboplatin (the Scottish Randomised Trial in Ovarian Cancer, or SCOTROC, study in 1077 patients with grade Ic-IV ovarian carcinoma) supported these findings by showing a significant difference between the two treatments in tolerability profiles (Vasey and the Scottish Gynaecological Cancer Trials Group, 2001). A higher proportion of patients in the docetaxel arm than in the paclitaxel arm experienced grade IV neutropenia ( $80 v s 55 \%$ ), although this was reported by the authors not to have compromised dose delivery or patient safety. As already discussed, guidelines are in place to aid clinicians in the use of colony-stimulating factors in patients likely to be at risk of myelosuppression, and appropriate treatment of this type would be expected to minimise the incidence and severity of neutropenia in patients receiving docetaxel with carboplatin in future studies.

Of additional interest in this respect are the observations (reported earlier) of Hainsworth et al (1998), who showed no grade IV leucopenia in their study of weekly docetaxel in 35 patients with advanced ovarian cancer. This suggests that weekly schedules of docetaxel may offer a clinical alternative for the minimisation of myelosuppression.

\section{Neurotoxicity}

Paclitaxel use is associated with neuropathy that is predominantly sensory. This adverse effect appears to be dose-related, and is usually observed $24-72 \mathrm{~h}$ after single doses exceeding $250 \mathrm{mg} \mathrm{m}^{-2}$ or after multiple doses of $135-200 \mathrm{mg} \mathrm{m}^{-2}$. Patients who have received previous treatment with neurotoxic drugs appear in particular to be predisposed to this reaction. The neuropathy typically manifests initially as a burning or tingling sensation in the glove and stocking areas, and can progress to motor weakness with continued administration of the drug (Pazdur et al, 1993).

The severity and frequency of peripheral neuropathy with paclitaxel may be related to infusion times in addition to dose, with more rapid infusions being associated with higher incidences. This is illustrated by results from two pivotal phase III studies that established the superiority of 3-weekly cisplatin plus paclitaxel over cisplatin plus cyclophosphamide in a total of 1057 evaluable patients with advanced ovarian cancer. Cisplatin and cyclophosphamide were given at the same dosages in both studies (75 and
$750 \mathrm{mg} \mathrm{m}^{-2}$, respectively), but in one study a $24-\mathrm{h}$ infusion of paclitaxel $135 \mathrm{mg} \mathrm{m}^{-2}$ was given (McGuire et al, 1996), whereas a 3-h infusion of $175 \mathrm{mg} \mathrm{m}^{-2}$ was used in the other (Piccart et al, 2000). There was no significant difference between treatments in incidence or severity of neuropathy in the 24-h infusion study (grade III-IV neurological symptoms in $4 \%$ of patients in each group); however, in the 3-h infusion study a marked neuropathic effect occurred in $19 \%$ of patients receiving cisplatin-paclitaxel compared with $1 \%$ of patients treated with cisplatin-cyclophosphamide (Figure 1).

Concerns over the neurotoxicity of combinations of paclitaxel with carboplatin have been raised by several authors. Three key comparative trials of paclitaxel-cisplatin $v s$ paclitaxel-carboplatin - the Dutch-Danish trial (Neijt et al, 2000), the Gynecologic Oncology Group (GOG) 158 study (Ozols et al, 2003) and the Arbeitsgemeinschaft Gynaekologische Onkologie (AGO) trial (du Bois et al, 2003) - reported similar efficacy for both combination regimens in patients with advanced ovarian cancer but less neurotoxicity with carboplatin than cisplatin. Nevertheless, as shown in Table 2, a noteworthy fraction of carboplatin recipients were affected by this adverse effect in the Dutch-Danish and AGO trials. According to the recent report of the GOG 158 trial (Ozols et al, 2003), 28\% of patients who received carboplatin with paclitaxel $(n=400)$ compared with $31 \%$ in the cisplatin-paclitaxel arm $(n=392)$ were affected by grade II-IV neurotoxicity.

Peripheral neuropathy and myalgia/arthralgia have also been reported in patients receiving docetaxel, but to a lesser extent than in those receiving paclitaxel; neurotoxicity is also generally not dose limiting for docetaxel (Fulton and Spencer, 1996). Although fewer data are available for docetaxel than for paclitaxel in ovarian cancer, two studies of combination chemotherapy with docetaxel (dosages ranged from $40-85 \mathrm{mg} \mathrm{m}^{-2}$ every 3 weeks) and carboplatin (AUC 4-6) in a total of 189 patients with ovarian and other carcinomas both showed incidences of peripheral neuropathy (Markman et al, 2001) or grade II-III neurotoxicity (Vasey et al, 2001) of only $6 \%$.

Preliminary results from the SCOTROC study (Vasey and the Scottish Gynaecological Cancer Trials Group, 2001) supported these findings: grade II - III sensory neuropathy was reported in 10 and $28 \%$ of patients $(P<0.001)$ in the docetaxel-carboplatin and paclitaxel-carboplatin groups, respectively. Most recent results (Vasey and the Scottish Gynaecological Cancer Trials Group, 2002) are similar: patients in the docetaxel arm reported less tingling in hands and feet and numbness in fingers and toes than those in the

$\square$ Cyclophosphamide + cisplatin $\quad \square$ Paclitaxel + cisplatin

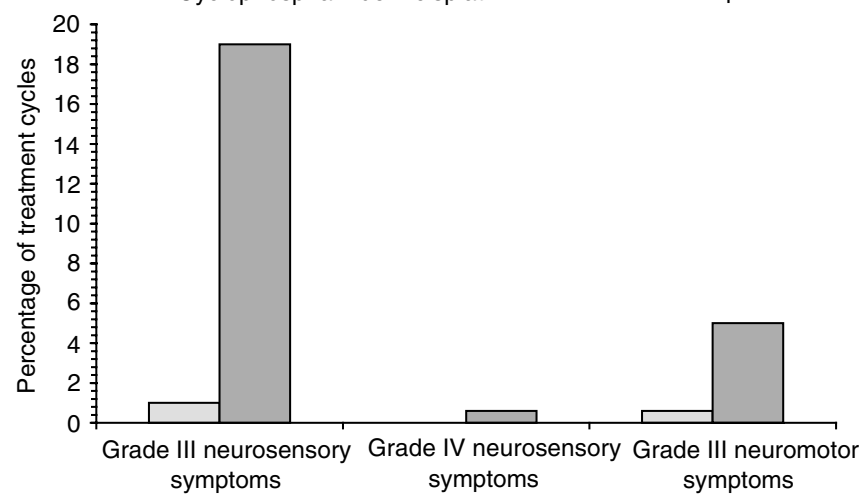

Figure I Neurosensory/neuromotor adverse events across all treatment cycles in 675 assessable patients with stage Ilb-IV ovarian cancer in a phase III study (Piccart et al, 2000). Patients were randomly assigned to receive (i) paclitaxel $175 \mathrm{mg} \mathrm{m}^{-2}$ over $3 \mathrm{~h}$ followed by cisplatin $75 \mathrm{mg} \mathrm{m}^{-2}$ or (ii) cyclophosphamide $750 \mathrm{mg} \mathrm{m}^{-2}$ followed by cisplatin $75 \mathrm{mg} \mathrm{m}^{-2}$ for six to nine cycles. 
Table 2 Neurotoxicities reported in the Dutch-Danish ${ }^{\mathrm{a}}$ and $A G \mathrm{O}^{\mathrm{b}}$ studies of paclitaxel-cisplatin vs paclitaxel-carboplatin

\begin{tabular}{|c|c|c|c|c|}
\hline \multirow[b]{2}{*}{ Treatment arm } & \multicolumn{2}{|c|}{ Dutch-Danish $(n=208)$} & \multirow{2}{*}{$\begin{array}{c}\text { AGO }(n=772) \\
\begin{array}{c}\text { Grade III-IV peripheral } \\
\text { neuropathy }(\%)\end{array}\end{array}$} & \multirow{2}{*}{$\begin{array}{c}\text { GOG I58 }(n=792) \\
\text { Grade III } \\
\text { neurotoxicity (\%) }\end{array}$} \\
\hline & $\begin{array}{c}\text { Grade II } \\
\text { neurotoxicity (\%) }\end{array}$ & $\begin{array}{c}\text { Grade III } \\
\text { neurotoxicity (\%) }\end{array}$ & & \\
\hline Paclitaxel+cisplatin & 26 & 6 & 14 & 8 \\
\hline Paclitaxel+carboplatin & 17 & 3 & 7 & 7 \\
\hline
\end{tabular}

$\square$ Docetaxel + carboplatin (DCb)

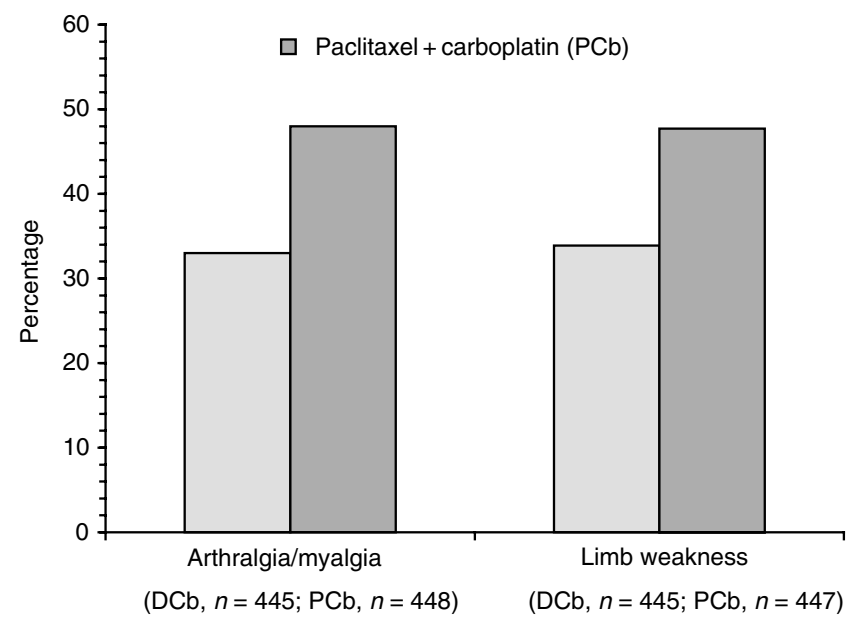

Figure 2 Incidences of arthralgic/myalgic symptoms and weakness in arms and legs reported in the multicentre phase III SCOTROC study of 3weekly carboplatin to AUC 5 with either paclitaxel $175 \mathrm{mg} \mathrm{m}^{-2}$ infused over $3 \mathrm{~h}$ or docetaxel $75 \mathrm{mg} \mathrm{m}^{-2}$ over I h (Vasey and the Scottish Gynaecological Cancer Trials Group, 2002). Chemotherapy was given for up to six cycles as first-line treatment in women with grade Ic-IV ovarian cancer. Patient numbers denote those available for assessment of each adverse event shown.

paclitaxel arm during treatment $(P<0.001)$ and $6(P<0.001)$ and $10(P<0.005)$ months after randomisation. Arthralgia and myalgia were also reported significantly less frequently by docetaxel than paclitaxel recipients (Figure 2). Note that these data were obtained with the EORTC's OV28 ovarian cancer module as described later in this review.

\section{Other adverse events}

In general, proportions of patients experiencing grade III-IV nonhaematological adverse events such as arthralgia, myalgia, diarrhoea, hypersensitivity and fluid retention remain below $10 \%$ when premedication is administered with the taxanes as recommended (Boehnke Michaud et al, 2000; Kaye 2000; Vasey et al, 2001). Fluid retention syndrome appears to be confined to patients receiving docetaxel, although mild peripheral oedema has been reported with paclitaxel (Boehnke Michaud et al, 2000). The first sign of fluid retention is weight gain: early treatment with diuretics is effective in limiting the severity of the condition, which is most likely to be of concern in patients with congestive heart failure or other comorbid conditions (Boehnke Michaud et al, 2000).

As with the majority of chemotherapeutic agents, alopecia is common with either docetaxel or paclitaxel, with the whole body being affected approximately 10-14 days after the beginning of therapy (Boehnke Michaud et al, 2000). Although this adverse effect can have significant effects on body image, it does not pose any clinical risk to the patient.

\section{Quality of life}

Since the definition over 50 years ago by the World Health Organization of health as not only the absence of disease and infirmity but also as the presence of physical, mental and social well-being, QoL issues have assumed increasing prominence in healthcare practice and research (Testa and Simonson, 1996). Accordingly, the goals of chemotherapy in advanced cancer should include improvement in QoL as well as increased duration of survival. Quality of life is therefore assuming ever-greater importance in the evaluation of cancer treatments.

Quality of life measurements and interpretation depend at least in part on patient characteristics, including stage and extent of disease, and on the type of treatment received, but there is general agreement on the usefulness of QoL assessments in the comparison of different therapies that confer similar survival in advanced cancer (Pignata et al, 2001). Alternatively, a clinically superior treatment may be so poorly tolerated that any survival advantage gained may not be sufficient to offset losses in QoL.

QoL issues of special relevance in patients with gynaecological (and therefore ovarian) cancer include limitations of sexual activity, early menopause, chemotherapy-induced toxicity and loss of body image (Pignata et al, 2001). Furthermore, it has been shown that awareness of severe disease is more frequent among women with ovarian cancer than among women with other types of malignancy (Porzio et al, 1999). Most generic QoL tools do not adequately capture disease-specific information or address treatment-related issues relevant to women with ovarian cancer, but the EORTC has recently developed an instrument specifically to deal with this problem.

\section{The EORTC OV28 module}

The EORTC core QoL questionnaire QLQ-C30 was introduced in the early 1990s as a psychometrically robust and cross-culturally acceptable questionnaire designed to be applicable to a broad spectrum of cancer patients, and is now in widespread use worldwide. The development of OV28 as a QoL instrument for patients with ovarian cancer follows the EORTC's strategy of supplementing the generic QLQ-C30 questionnaire with diseaseand/or treatment-specific modules to address issues of relevance to particular patient groups (Cull et al, 2001).

The provisional module as described in 2001 (Cull et al, 2001) has 28 items assessing abdominal symptoms, peripheral neuropathy, other chemotherapy-related side effects, hormonal symptoms, body image, attitude to disease and treatment and sexual functioning. The first 24 items of the module (items $31-54$ as added to QLQ-C30), excluding questions on sexual functioning, have been assessed in a scaling analysis carried out with data from 277 patients participating in the SCOTROC trial (Cull et al, 2001; Vasey and the Scottish Gynaecological Cancer Trials Group, 2001, 2002). The mean scale scores were found to discriminate between 
Table 3 Examples of QoL assessments undertaken in studies in women with advanced (unless stated otherwise) ovarian cancer

\begin{tabular}{|c|c|c|c|}
\hline Study & $\begin{array}{l}\text { Drugs given } \\
\text { (no. of patients) }\end{array}$ & QoL instruments & Summary of findings \\
\hline $\begin{array}{l}\text { Bodurka-Bevers } \\
\text { et al (2000) }\end{array}$ & $\begin{array}{l}\text { Various ( } 246-74 \% \text { with } \\
\text { advanced disease) }\end{array}$ & $\begin{array}{l}\text { Assessment of physical, functional, } \\
\text { emotional and social/family well- } \\
\text { being. CES-D, State Anxiety } \\
\text { subscale of Spielberger State-Trait } \\
\text { Anxiety Inventory, Zubrod scores }\end{array}$ & $\begin{array}{l}\text { Performance status related to depression, anxiety and } \\
\text { QoL problems, except for social well-being }\end{array}$ \\
\hline Ersek et al (1997) & $\begin{array}{l}\text { Various (study in } 152 \\
\text { survivors - all disease } \\
\text { stages) }\end{array}$ & QoL - Cancer Survivors tool & $\begin{array}{l}\text { QoL moderately high despite negative findings related } \\
\text { to facets of the illness and treatment experiences. } \\
\text { Qualitative results reflect complexity of the cancer } \\
\text { experience }\end{array}$ \\
\hline $\begin{array}{l}\text { Kornblith et al } \\
\text { (1995) }\end{array}$ & $\begin{array}{l}\text { Various ( }|5|-86 \% \text { with } \\
\text { advanced disease) }\end{array}$ & $\begin{array}{l}\text { Memorial Pain Assessment Card; } \\
\text { Memorial Symptom Assessment } \\
\text { Scale; MHI; FLIC; KPS }\end{array}$ & $\begin{array}{l}\text { QoL assessed at 3-month intervals. Impaired physical } \\
\text { functioning (FLIC) most important predictor of } \\
\text { psychological distress }(\mathrm{MHI}) \text { at baseline. Significant } \\
\text { differences in all QoL scales between patients with } \\
\text { KPS } \leqslant 80 \text { and those with KPS } \geqslant 90 \text {. Need for improved } \\
\text { and more frequent assessment of psychological status } \\
\text { stressed }\end{array}$ \\
\hline Lakusta et al (200I) & $\begin{array}{l}\text { First-line cisplatin and } \\
\text { second-line carboplatin } \\
\text { (chart review of } 60 \\
\text { patients) }\end{array}$ & EORTC QLQ-C30 & $\begin{array}{l}\text { Less impact of carboplatin than cisplatin on QoL. } \\
\text { Improved QoL over time in patients with recurrent } \\
\text { disease supports palliative use of carboplatin }\end{array}$ \\
\hline Schink et al (200I) & Paclitaxel+carboplatin (59) & FACT-OC & $\begin{array}{l}\text { Improvement in QoL and physical well-being scores } \\
\text { during this study of outpatient treatment }\end{array}$ \\
\hline $\begin{array}{l}\text { Willemse et al } \\
\text { (1990) }\end{array}$ & $\begin{array}{l}\text { Cyclophosphamide+ } \\
\text { doxorubicin+cisplatin (68) }\end{array}$ & TWiST & $\begin{array}{l}\text { Correction of progression-free survival with TWiST } \\
\text { suggested as being suitable for comparing effect of } \\
\text { differing chemotherapy schedules on QoL }\end{array}$ \\
\hline $\begin{array}{l}\text { Willemse et al } \\
\text { (1992) }\end{array}$ & $\begin{array}{l}\text { Carboplatint } \\
\text { cyclophosphamide (76) }\end{array}$ & TWiST & $\begin{array}{l}\text { QoL as measured by TWiST significantly better than } \\
\text { cyclophosphamide-doxorubicin-cisplatin (CAP-5) by } \\
\text { comparison with historical control group }(n=65)\end{array}$ \\
\hline
\end{tabular}

Abbreviations: CES-D = Center for Epidemiologic Studies-Depression scale; EORTC QLQ-C30 = European Organization for the Research and Treatment of Cancer Quality of Life Questionnaire core items; FACT-OC = Functional Assessment of Cancer Therapy - Ovarian Cancer scale; FLIC = Functional Living Index - Cancer; KPS $=$ Karnofsky Performance Scale; $\mathrm{MHI}=$ Mental Health Inventory; $\mathrm{QoL}=$ quality of life; TWiST = time without symptoms of disease or treatment.

trial patients before and after starting chemotherapy, and the OV28 module was indicated as a promising tool for the assessment of QoL of women with ovarian cancer. Emerging data from the SCOTROC study (Vasey and the Scottish Gynaecological Cancer Trials Group, 2002) show further the utility of OV28, particularly in terms of effect of chemotherapy on well-being (see neurotoxicity discussion earlier and Figure 2).

Quality of life has been investigated in patients with ovarian cancer in various studies, some of which are summarized in Table 3. A review of 20 papers, 10 of which were treatment-related QoL assessments and 10 of which dealt with other issues including psychometric evaluation, was published in the mid-1990s, and concluded that the Rotterdam Symptom Checklist and EORTC QLQ-C30 were the most appropriate instruments for use in patients with ovarian cancer at that time (Montazeri et al, 1996). However, this review was published before the development and introduction of the OV28 module. Thus, despite the inability of any instrument available to date to measure chemotherapy-related QoL directly, the lack of any comparative QoL data specific to patients receiving taxane therapy has resulted in considerable interest in the publication of the final analyses of the SCOTROC results.

\section{Psychological distress and QoL in ovarian cancer patients}

As indicated in Table 3, studies are available to show the effect of psychological distress on patients with ovarian cancer. Kornblith et al (1995) examined physical, social and psychological well-being with a variety of instruments in 151 ovarian cancer patients (see Table 3), and reported significant psychological distress (expressed as 1.5 s.d. above a predetermined nationwide community sample standard in Mental Health Inventory psychological distress scores) in one-third of patients at study entry. Interestingly, but perhaps not surprisingly, impaired physical functioning was the most important predictor of heightened psychological distress.

A subsequent study evaluated psychological distress and QoL and examined the relationship between these problems and health and demographic variables in 246 patients with ovarian cancer who completed questionnaires (Bodurka-Bevers et al, 2000). Clinically significant depression and anxiety, assessed with the Center for Epidemiologic Studies Depression scale (CES-D) and State Anxiety subscale of the Spielberger State-Trait Anxiety Inventory, were found to be more prevalent than had been expected. Clinical depression was shown in $21 \%$ of patients, while $29 \%$ scored above the 75 th percentile for anxiety. Further studies of screening and treatment of psychological distress were recommended to improve QoL outcomes in women with ovarian cancer.

Of particular interest in the context of this review is a recent study involving a chart review of 60 women with ovarian cancer undergoing chemotherapy with platinum agents (Lakusta et al, 2001). Analysis of EORTC QLQ-C30 questionnaire responses from these patients was used to relate biomedical variables to QoL outcomes and to compare patients receiving cisplatin as first-line therapy with those receiving palliative carboplatin for recurrent disease. Women receiving first-line cisplatin reported more appetite disturbance, diarrhoea and nausea than those on palliative carboplatin. Most notably, QoL declined over time in the newly diagnosed patients, whereas improvements were noted in those with recurrent disease, and lower QoL was found to predict death within 12 months of starting treatment. It was concluded on the basis of these results that the EORTC QLQ-C30 instrument can be used to test clinical assumptions and to influence treatment programmes in women with ovarian cancer undergoing che- 
motherapy. Furthermore, the findings appear to support the use of carboplatin as a palliative agent in advanced disease. They also indicate the potential utility of structured QoL assessments before clinic appointments as a means of improving overall patient care.

\section{CONCLUSIONS}

Despite similarities in chemical structure and mode of action, docetaxel and paclitaxel cannot be regarded as having the same properties when used clinically. Study results have shown that the substitution of docetaxel for paclitaxel in a platinum-based doublet does not compromise efficacy, but that such substitution may confer benefits in terms of convenience to patients and toxicity. The reduced infusion time generally used with docetaxel ( 1 rather than $3 \mathrm{~h}$ ), together with the need for premedication with oral dexamethasone only, is likely to be more convenient and to reduce the stress placed on patients by their treatment relative to paclitaxel. Docetaxel-carboplatin has also been associated with

\section{REFERENCES}

Aventis Pharmaceuticals Products Inc. Taxotere ${ }^{\circledR}$ (docetaxel) for injection concentrate (2002) Bridgewater, NJ

Bodurka-Bevers D, Basen-Engquist K, Carmack CL, Fitzgerald MA, Wolf JK, de Moor C, Gershenson DM (2000) Depression, anxiety, and quality of life in patients with epithelial ovarian cancer. Gynecol Oncol (3 Part 1) 78: $302-308$

Boehnke Michaud L, Valero V, Hortobagyi G (2000) Risks and benefits of taxanes in breast and ovarian cancer. Drug Saf 23: $401-428$

Cull A, Howat S, Greimel E, Waldenstrom A-C, Arraras J, Kudelka A, Chauvenet L, Gould A, for the EORTC Quality of Life Group and the Scottish Gynaecological Cancer Trials Group (2001) Development of a European Organization for Research and Treatment of Cancer questionnaire module to assess the quality of life of ovarian cancer patients in clinical trials: a progress report. Eur J Cancer 37: 47-53

du Bois A, Lück H, Meier W, Adams H-P, Möbus V, Costa S, Bauknecht T, Richter B, Warm M, Schröder W, Olbricht S, Nitz U, Jackisch C, Emons G, Wagner U, Kuhn W, Pfisterer J (2003) A randomized clinical trial of cisplatin/paclitaxel versus carboplatin/paclitaxel as first-line treatment of ovarian cancer. J Natl Cancer Inst 95: 1320-1329

Dunton CJ (1997) New options for the treatment of advanced ovarian cancer. Semin Oncol 24(Suppl 5): S5-2-S5-11

Ersek M, Ferrell BR, Dow KH, Melancon CH (1997) Quality of life in women with ovarian cancer. West J Nurs Res 19: 334-350

European Society of Medical Oncology (2001) ESMO recommendations for the application of haematopoietic growth factors (hGFs). Ann Oncol 12: $1219-1220$

Fennelly D, Aghajanian C, Shapiro F, O'Flaherty C, McKenzie M, O'Connor C, Tong W, Norton L, Spriggs D (1997) Phase I and pharmacologic study of paclitaxel administered weekly in patients with relapsed ovarian cancer. J Clin Oncol 15: 187- 192

Fulton B, Spencer CM (1996) Docetaxel: a review of its pharmacodynamic and pharmacokinetic properties and therapeutic efficacy in the management of metastatic breast cancer. Drugs 51: 1057-1092

Gorbounova V, Khokhlova S, Orel N (2000) Docetaxel and cisplatin as firstline chemotherapy in patients with advanced ovarian cancer (abstract). Proc Am Soc Clin Oncol 20: 1536

Guastalla JP, Ferrero JM, Dieras V (1999) Cisplatin - docetaxel (Taxotere) in first line treatment of advanced ovarian cancer (OC): a GINECO phase II trial (abstract). Proc Am Soc Clin Oncol 18: 1448

Hainsworth JD, Burris III HA, Erland JB, Thomas M, Greco FA (1998) Phase I trial of docetaxel administered by weekly infusion in patients with advanced refractory cancer. J Clin Oncol 16: 2164-2168

Kaye SB (2000) Intravenous chemotherapy for ovarian cancer-the state of the art? Int J Gynecol Cancer 10(Suppl 1): 19-25

Kaye SB (2001) Future directions for the management of ovarian cancer. Eur J Cancer 37: S19-S23

Kolevska T, Smith D, Wertheim I (2001) A phase II study of docetaxel and carboplatin in the treatment of sub-optimally debulked stage III and IV ovarian cancer (abstract). Proc Am Soc Clin Oncol 20: 2497 reduced frequency and severity of neurotoxicity relative to paclitaxel/carboplatin in clinical studies in patients with ovarian cancer. Higher incidences of neutropenia have been reported in patients receiving the docetaxel combination, but this is reported to be easily managed and is not associated with increases in rates of treatment discontinuation or death.

There are currently few data relevant to QoL in patients receiving taxane-platinum combinations for ovarian cancer, and QoL instruments cannot measure directly chemotherapy-related adverse effects. Nevertheless, the need for meaningful QoL assessments and the subsequent implications for treatment plans have become clear over the past decade, and results gained with the instruments available in comparative trials are awaited with interest. Familiarity of clinicians with differences between regimens in terms of toxicity, dosage and administration and QoL issues as data emerge and accumulate will assist in the optimisation of treatment decisions in patients with ovarian cancer.
Kornblith AB, Thaler HT, Wong G, Vlamis V, Lepore JM, Loseth DB, Hakes T, Hoskins WJ, Portenoy RK (1995) Quality of life of women with ovarian cancer. Gynecol Oncol 59: 231-242

Kurihara M, Sakamoto H, Ohta Y, Takami T, Takami M, Nakayama Y, Murata H, Ohtani K, Masaoka N, Yamamoto T, Satoh K (2001) Patient compliance and the quality of life are well maintained in weekly paclitaxel and carboplatin therapy for advanced gynecologic cancers in Japanese women. Gan To Kagaku Ryoho 28: 55-61 (in Japanese)

Lakusta CM, Atkinson MJ, Robinson JW, Nation J, Taenzer PA, Campo MG (2001) Quality of life in ovarian cancer patients receiving chemotherapy. Gynecol Oncol 81: 490-495

Lister-Sharp D, McDonagh MS, Khan KS, Kleijnen J (2000) A rapid and systematic review of the effectiveness and cost-effectiveness of the taxanes used in the treatment of advanced breast and ovarian cancer. Health Technol Assess 4: 1-113

Markman M, Hall J, Spitz D, Weiner S, Carson L, Van Le L, Baker M (2002) Phase II trial of weekly single-agent paclitaxel in platinum/paclitaxelrefractory ovarian cancer. J Clin Oncol 20: 2365-2369

Markman M, Kennedy A, Webster K, Peterson G, Kulp B, Balinson J (2001) Combination chemotherapy with carboplatin and docetaxel in the treatment of cancers of the ovary and fallopian tube and primary carcinoma of the peritoneum. J Clin Oncol 19: $1901-1905$

McGuire WP, Hoskins WJ, Brady MF, Kucera PR, Partridge EE, Look KY, Clarke-Pearson DL, Davidson M (1996) Cyclophosphamide and cisplatin compared with paclitaxel and cisplatin in patients with stage III and stage IV ovarian cancer. $N$ Engl J Med 334: 1-6

Mead Johnson Oncology Products Taxol (paclitaxel) injection. Princeton, NJ, 2000

Meyer A, Huober JB, Goerner R (1999) Chemotherapy with carboplatin/ docetaxel and recurrent epithelial ovarian cancer (abstract). Proc Am Soc Clin Oncol 20: 1465

Montazeri A, McEwen J, Gillis CR (1996) Quality of life in patients with ovarian cancer: current state of research. Support Care Cancer 4: 169179

National Library of Medicine Consensus Conference Reports 1992-1994. Ovarian cancer: screening, treatment, and follow-up. NIH Consens Statement Online 1994 April 5-7. Available from: URL: http:// hstat.nlm.nih.gov (accessed 13 May 2002)

Neijt JP, Engelholm SA, Tuxen MK, Sorensen PG, Hansen M, Sessa C, de Swart CA, Hirsch FR, Lund B, van Houwelingen HC (2000) Exploratory phase III study of paclitaxel and cisplatin versus paclitaxel and carboplatin in advanced ovarian cancer. J Clin Oncol 18: 3084-3092

Ozer H, Armitage JO, Bennett CL, Crawford J, Demetri GD, Pizzo PA, Schiffer CA, Smith TJ, Somlo G, Wade JC, Wade JL, Winn RJ, Wozniak AJ, Somerfield MR, American Society of Clinical Oncology (2000) 2000 update of recommendations for the use of hematopoietic colonystimulating factors: evidence-based, clinical practice guidelines. American Society of Clinical Oncology Growth Factors Expert Panel. J Clin Oncol 18: $3558-3585$ 
Ozols RF, Bundy BN, Greer BE, Fowler JM, Clarke-Pearson D, Burger RA, Mannel RS, DeGeest K, Hartenbach EM, Baergen R, Gynecologic Oncology Group (2003) Phase III trial of carboplatin and paclitaxel compared with cisplatin and paclitaxel in patients with optimally resected stage III ovarian cancer: a Gynecologic Oncology Group study. J Clin Oncol 21: 3194-3200

Pazdur R, Kudelka AP, Kavanagh JJ, Cohen PR, Rabert MN (1993) The taxoids: paclitaxel $\left(\right.$ Taxol $\left.^{\circledR}\right)$ and docetaxel $\left(\right.$ Taxotere $\left.{ }^{\mathbb{R}}\right)$. Cancer Treat Rev 19: $351-386$

Piccart MJ, Bertelsen K, James K, Cassidy J, Mangioni C, Simonsen E, Stuart G, Kaye S, Vergote I, Blom R, Grimshaw R, Atkinson RJ, Swenerton KD, Trope C, Nardi M, Kaern J, Tumolo S, Timmers P, Roy JA, Lhoas F, Lindvall B, Bacon M, Birt A, Andersen JE, Zee B, Paul J, Baron B, Pecorelli S (2000) Randomized intergroup trial of cisplatin-paclitaxel versus cisplatin-cyclophosphamide in women with advanced epithelial ovarian cancer: three-year results. J Natl Cancer Inst 92: 699-708

Pignata S, Ballatori E, Favalli G, Scambia G (2001) Quality of life: gynaecological cancers. Ann Oncol 12(Suppl 3): S37-S42

Porzio G, Ruggeri B, Marchetti P, Ficorella C, Morese R, Mattei A, Ballatori E (1999) Awareness of disease: a cross-sectional study of ovarian cancer patients (abstract) . Proceedings of the Seventh Biennial Meeting of the International Gynaecologic Cancer Society, Rome, 26-30 September, pp. $281-284$

Schink JC, Weller E, Harris LS, Cella D, Gerstner J, Falkson C, Wadler S (2001) Outpatient taxol and carboplatin chemotherapy for suboptimally debulked epithelial carcinoma of the ovary results in improved quality of life: an Eastern Cooperative Oncology Group phase II study (E2E93). Cancer J 7: $155-164$

Testa MA, Simonson DC (1996) Assessment of quality-of-life outcomes. $N$ Engl J Med 334: 835 - 840
Vasey PA, on behalf of the Scottish Gynaecological Cancer Trials Group (2001) Preliminary results of the SCOTROC trial: a phase III comparison of paclitaxel-carboplatin (PC) and docetaxel-carboplatin (DC) as a first-line chemotherapy for stage Ic-IV epithelial ovarian cancer (EOC) (abstract). Proc Am Soc Clin Oncol 20: 804

Vasey PA, on behalf of the Scottish Gynaecological Cancer Trials Group (2002) Survival and longer-term toxicity results of the SCOTROC study: docetaxel - carboplatin (DC) vs. paclitaxel-carboplatin (PC) in epithelial ovarian cancer (EOC) (abstract). Proc Am Soc Clin Oncol 21: 804

Vasey PA, Atkinson R, Coleman R, Crawford M, Cruickshank M, Eggleton P, Fleming D, Graham J, Parkin D, Paul J, Reed NS, Kaye SB (2001) Docetaxel-carboplatin as first line chemotherapy for epithelial ovarian cancer. Br J Cancer 84: $170-178$

Vasey PA, Paul J, Birt A, Junor EJ, Reed NS, Symonds RP, Atkinson R, Graham J, Crawford SM, Coleman R, Thomas H, Davis J, Eggleton SP, Kaye SB (1999) Docetaxel and cisplatin in combination as first-line chemotherapy for advanced epithelial ovarian cancer. Scottish Gynaecological Cancer Trials Group. J Clin Oncol 17: 2069-2080

Vorobiof DA, Rapoport BL, Chasen MR, Cohen GL, Mahomed R, Karime M (2003) Phase II clinical trial of carboplatin and docetaxel in patients with metastatic ovarian cancer: active combination with low incidence of peripheral neuropathy. Int J Gynecol Cancer 13: 287-291

Willemse PH, de Vries EG, Kloppenburg M, Fontein DL, Aalders JG, Boonstra H, Mulder NH, Sleijfer DT (1992) Carboplatin with cyclophosphamide in patients with advanced ovarian cancer: an efficacy and quality-adjusted survival analysis. Int $J$ Gynecol Cancer 2: $236-243$

Willemse PH, van Lith J, Mulder NH, Aalders JG, Bouma J, de Vries EG, Sleijfer DT (1990) Risks and benefits of cisplatin in ovarian cancer. A quality-adjusted survival analysis. Eur J Cancer 26: 345 - 352 